This paper should be cited as:

Gallagher L, Clarke M, Begley C. Determinants of breastfeeding initiation in Ireland. Irish Journal of Medical Science. 2015. 185 (3): 663-668

\title{
Determinants of breastfeeding initiation in Ireland.
}

Authors:

Louise Gallagher ${ }^{1}$, Trinity College Dublin

Professor Cecily Begley², Trinity College Dublin

Professor Mike Clarke ${ }^{3}$, Trinity College Dublin

${ }^{1}$ Corresponding author: Assistant Professor, Trinity College Dublin, School of Nursing and Midwifery, 24 D’Olier Street, Dublin 2, Email: gallagl8@tcd.ie, Telephone: 01 8963874.

2 Professor, Trinity College Dublin, School of Nursing and Midwifery, 24 D'Olier Street, Dublin 2.

${ }^{3}$ Adjunct Professor, Trinity College Dublin, School of Nursing and Midwifery, 24 D'Olier Street, Dublin 2 


\section{Introduction}

Breastfeeding is promoted worldwide to ensure optimum infant and maternal outcomes. The World Health Organisation [1] recommends that, wherever possible, infants should be fed exclusively on breast milk until six months of age and that breastfeeding should continue as part of the infant's diet for at least two years.

Breastfeeding rates in Ireland have historically been low when compared to other European countries, and stood at 44\% in 2005 [2] Among 29 countries reported in 2003, Ireland had the lowest initiation rate behind Malta and France [3]. Targets set for Ireland in 2005 were to raise breastfeeding initiation and duration rates by two percentage points per year and to increase the breastfeeding rate by $4 \%$ per year among families from lower socioeconomic groups [2].

Currently, there is no national, comprehensive system of collating data relating to breastfeeding at birth, or in the longer postnatal period following discharge from maternity care in Ireland. This makes it difficult to measure rates against targets to assess progress. The Economic and Social Research Institute figures from the national perinatal reporting system represent the only national data source currently available 
on infant feeding in Ireland, but there is a 2-year time lag between collection and availability.

In order to address the deficit in data, the Health Service Executive (HSE) commissioned a national study to determine the rate and duration of breastfeeding. The study aimed to assess the rate of exclusive and partial breastfeeding at three time periods: from birth to 48 hours, at 3-4 months following birth, and when the infant was 6-7 months old. Data were collected from April to October 2008 and descriptive analysis took place throughout 2009. Multivariate analysis was undertaken subsequently to determine the factors influencing the initiation and continuation of breastfeeding.

\section{Methods}

Ethical approval was granted by the Faculty of Health Sciences Ethics Committee, Trinity College Dublin, and all hospitals involved.

Phase 1 involved a survey of infant feeding practices at 48 hours or at discharge, whichever was earlier. Women who gave birth to live babies at 24 weeks gestation or greater in the 20 maternity hospitals/units (or under the care of the 19 independent midwives) in the Republic of Ireland during the month of April 2008 were asked to take part, and 2,527 did so, a 33\% response rate. 
All twenty maternity units and all nineteen independent midwives participated in this survey, providing a nationally representative sample of mothers for the Republic of Ireland. All mothers who were seen by the independent midwives responded $(n=8$, $100 \%)$, but response rates for each of the hospitals varied from $6 \%$ to $70 \%$, thus data for initiation and prevalence of breastfeeding by hospital of birth could not be relied upon for accuracy. Midwives were asked to distribute the questionnaire because of their access to mothers and their ability to assess those who met the inclusion criteria.

It is impossible to determine how many women were offered the opportunity to participate but declined. To assess the effect that non-response to Phase 1 may have had on the findings, comparative analysis was undertaken with the National Perinatal Reporting System (NPRS) 2006 data [4]. This showed that the sample achieved in this survey was broadly similar in demographic terms (mean age, marital status and birth order), to the sample achieved in the NPRS 2006 survey.

Inclusion criteria

All women who gave birth to a live infant, at 24 weeks gestation or greater, during the recruitment period for the study were eligible to participate.

\section{Exclusion criteria}

Women were not eligible if they had given birth to a stillborn baby or their baby had died within the first 48 hours after birth. 
Phase 2 (at 3-4 months postnatal), consisted of a postal survey of all participating women, of whom $72 \%(1,826)$ responded. A further postal survey was also used for Phase 3 (6-7 months postnatal), for the 621 mothers who were breastfeeding when they completed Phase 2. Of these, 461 women (74\%) responded.

Questionnaires for all phases were adapted from a well-tested instrument used in the United Kingdom [5]. Final questionnaires were pre-tested for face/content validity with a total of 38 postnatal women and 18 clinicians. A test-re-test exercise with 20 postnatal women gave a Kappa statistic of 0.87 to 1.0, indicating very good reliability. Surveys were translated into Polish, Latvian, Lithuanian, Irish, French and Portuguese so that these would be available should any of the women prefer to use them.

Quantitative data were analysed using The Statistical Package for the Social Sciences [6]. Sample characteristics are described in this paper using percentages, means or medians and standard deviations and comparative analyses used chi-square tests.

Lack of precision and consistency in defining breastfeeding has, in the past, led to problems with the interpretation of data and consequent difficulty in drawing comparisons between studies [7]. For this reason, the definitions recommended by the World Health Organization [8] were adopted in this study. Initiation of breastfeeding 
therefore includes all infants who have received breastmilk (either direct from the breast or expressed).

\section{Results}

The reported results are based on Phase 2 data $(n=1826)$, since the purpose of Phase 1 was primarily recruitment to the study. Initiation rates are consistent between both phases.

Forty-one percent of women ( $n=747)$ were having their first baby and $1072(59 \%)$ were having their second or subsequent baby (7 missing), consistent with National Perinatal Reporting System (NPRS) figures for women having their first (41.1\%) [4], or second and subsequent, baby (58.9\%) [4].

The majority had private health insurance $(66 \%, n=1,198)$, were married $(76 \%, n=1,374)$, and employed $(77 \%, n=1,388)$. Mean age was 31 years with $39 \%(n=659)$ aged $30-34$. This is also consistent with national figures, with $34 \%$ of mothers in this age group [4].

Fifty-six percent $(n=1,002)$ of mothers who responded to phase $2(n=1862)$ initiated breastfeeding at birth. By 48 hours (or on discharge, if that was earlier), $42 \%(n=1,064)$ of women were exclusively breastfeeding their babies, with a further $13 \%(n=307)$ breast and bottle feeding. 
Professional, managerial and technical workers were more likely to initiate breastfeeding ( $70 \%$ and $69 \%$ respectively) than those in non-manual, semi-skilled, skilled or manual employment (37-51\%).

Among mothers who discontinued breastfeeding between birth and completion of Phase 2 (3-4 months) of this survey, 35\% ( $n=153)$ did so in the first two weeks. By one month, more than half the mothers $(55 \%, n=243)$ were fully formula feeding. At $3-4$ months, the rate of exclusive breastfeeding had declined to $19 \%(n=347)$, with $66 \%$ of infants $(n=1,205)$ formula fed and $15 \%(n=271)$ partially breastfed at this point (Table 1$)$.

Table 1: Breastfeeding at different time periods

\begin{tabular}{|c|c|c|c|c|c|c|}
\hline \multirow{3}{*}{ Total $n=1,826$} & \multicolumn{6}{|c|}{ Incidence of feeding methods } \\
\hline & \multicolumn{2}{|c|}{ at first feed } & \multicolumn{2}{|c|}{ at discharge* } & \multicolumn{2}{|c|}{ at 3-4 months } \\
\hline & $\mathbf{N}$ & $\%$ & $\mathbf{N}$ & $\%$ & $\mathbf{N}$ & $\%$ \\
\hline Breast only & 1,002 & 56 & 881 & 49 & 347 & 19 \\
\hline Formula only & 774 & 43 & 755 & 41.9 & 1,205 & 66 \\
\hline Baby not feeding & 11 & 1 & 2 & 0.1 & N/A & N/A \\
\hline $\begin{array}{l}\text { Expressing Breast- } \\
\text { milk }\end{array}$ & N/A & N/A & 37 & 2 & N/A & N/A \\
\hline $\begin{array}{l}\text { Combination of } \\
\text { breast \& formula }\end{array}$ & N/A & N/A & 127 & 7 & 232 & 13 \\
\hline $\begin{array}{l}\text { Combination of } \\
\text { breast \& } \\
\text { water/juice }\end{array}$ & N/A & N/A & N/A & N/A & 39 & 2 \\
\hline Missing & 39 & & 24 & & 3 & \\
\hline
\end{tabular}


*Defined as the day they left hospital or at $48 \mathrm{hrs}$ in the case of a homebirth.

Irish women were less likely to initiate breastfeeding ( $n=785,52.6 \%)$ compared with British ( $n=40,64.5 \%)$, Polish $(n=37,82.2 \%)$ and other nationalities ( $n=138,74.6 \%)$. At 3-4 months, only 234 (16\%) Irish women were exclusively breastfeeding.

The age of the mother was a significant factor in the initiation of breastfeeding $(\chi 2=$ $40.08, d f=7, p<0.0001)$. The younger the mother when she gave birth, the less likely she was to initiate breastfeeding. Among mothers who initiated breastfeeding, those who were aged 40-44 were the most likely to be exclusively breastfeeding at 3-4 months ( $48 \%, n=25$ of the 82 women in that group). The average length of stay in hospital was three days, with $62 \%$ of women who gave birth in hospital $(n=1,107)$ going home on or before this point. Length of stay was not found to be a significant factor on rates of breastfeeding $(\chi 2=20.41, d f=5, p<0.157)$.

Those mothers who said that most of their friends breastfed their babies were more likely to breastfeed at birth (79\%) than those whose friends and family used formula feed $(47 \%)(\chi 2=96.56, d f=3, p=<0.0001)$. This suggests that peers are influential in a mother's choice of infant feeding method.

At 6-7 months, $18 \%$ of the 461 mothers who were breastfeeding at 3-4 months were exclusively breastfeeding ( $n=61)$. This is $6 \%$ of the 1002 mothers who had breastfed their infants at birth, and only $2.4 \%$ of the 2,527 mothers who joined the study. 
Univariate analysis revealed that maternal characteristics such as employment status, parity, social class, health insurance status, marital status and education level attained were significantly associated with breastfeeding initiation (Table 2).

Table 2: Factors associated with breastfeeding initiation

\begin{tabular}{|c|c|c|c|c|c|c|c|c|}
\hline Category* & & $\begin{array}{l}\text { Total } \\
\text { sample }\end{array}$ & $\begin{array}{l}\text { Breastfeeding at } \\
\text { birth }\end{array}$ & & $\begin{array}{c}\text { Formula } \\
\text { feeding at } \\
\text { birth }\end{array}$ & & $x^{2}$ & P-value \\
\hline & & $\%$ & $\mathbf{N}$ & $\%$ & $\mathbf{N}$ & $\%$ & & \\
\hline \multicolumn{9}{|c|}{ CSO classification } \\
\hline & $\begin{array}{l}\text { Professional, managerial } \\
\text { and technical }\end{array}$ & 41 & 485 & 70 & 213 & 30 & $\begin{array}{c}\chi^{2}=77.19 \\
d f=2\end{array}$ & $<0.0001$ \\
\hline & $\begin{array}{l}\text { Non-manual and skilled } \\
\text { manual }\end{array}$ & 48 & 402 & 50 & 398 & 50 & & \\
\hline & All other categories & 11 & 76 & 42 & 107 & 58 & & \\
\hline \multicolumn{9}{|c|}{ Employment status } \\
\hline & $\begin{array}{l}\text { Working for profit or } \\
\text { payment }\end{array}$ & 77 & 786 & 58 & 561 & 42 & & \\
\hline & Not working & 23 & 216 & 50 & 213 & 50 & $\begin{array}{c}\chi^{2}=8.47 \\
d f=1\end{array}$ & 0.004 \\
\hline \multicolumn{9}{|c|}{ Age ceased education } \\
\hline & Less than 18 years old & 7 & 96 & 39 & 149 & 61 & & \\
\hline & $18-20$ years old & 38 & 251 & 49 & 266 & 51 & & \\
\hline & $21-23$ years old & 46 & 355 & 70 & 153 & 30 & & \\
\hline & 24 and above & 9 & 194 & 72 & 77 & 28 & $\begin{array}{c}\chi^{2}=104.62 \\
d f=3\end{array}$ & $<0.0001$ \\
\hline \multicolumn{9}{|c|}{$\begin{array}{l}\text { Education level } \\
\text { attained }\end{array}$} \\
\hline & Lower Secondary or less & 8 & 46 & 32 & 96 & 68 & & \\
\hline & $\begin{array}{l}\text { Upper Secondary -third } \\
\text { level non degree }\end{array}$ & 52 & 428 & 48 & 460 & 52 & & \\
\hline & Primary degree or above & 40 & 520 & 72 & 204 & 28 & $\begin{array}{c}\chi^{2}=127.73 \\
d f=2\end{array}$ & $<0.0001$ \\
\hline Health Insu & & & & & & & & \\
\hline
\end{tabular}




$\begin{array}{llllllll}\text { Yes } & 66 & 710 & 61 & 285 & 39 & \\ \text { No } & 34 & 285 & 48 & 304 & 52 & \chi^{2}=24.11, \quad<0.0001 \\ & & & & & & d f=1\end{array}$

Marital Status

$\begin{array}{lcccccc}\text { Single } & 22 & 164 & 46 & 196 & 54 & \\ \text { Married } & 76 & 790 & 59 & 547 & 41 & \\ \text { All other categories } & 2 & 38 & 57 & 16 & 43 & \chi^{2}=25.41, \quad<0.0001 \\ & & & & & & d f=2\end{array}$

* Does not include infants not feeding yet due to small numbers

The behaviour and attributes of breastfeeding and formula feeding mothers were

compared by multivariate analysis using log-linear modelling. Small values of likelihood

ratio (chi-square) mean a good model in log-linear analysis.

Multivariate analysis revealed several significant relationships between socio-economic variables and initiation of breastfeeding. In particular, mothers' health insurance status mediates the effect of several other variables (Table 3).

Table 3: Observed frequencies and percentages for type of first feed, marital status and private health insurance

\begin{tabular}{|c|c|c|c|c|c|}
\hline \multicolumn{3}{|c|}{$\begin{array}{l}\text { Private } \\
\text { Health Ins }\end{array}$} & \multirow{2}{*}{$\begin{array}{l}\text { Initiated } \\
\text { Breastfeeding } \\
70\end{array}$} & \multirow{2}{*}{$\begin{array}{r}\text { Initiated } \\
\text { formula } \\
\text { feeding } \\
40\end{array}$} & \multirow{2}{*}{$\begin{array}{r}\text { Total } \\
110\end{array}$} \\
\hline Yes & Single & $\mathbf{N}$ & & & \\
\hline & & $\%$ & 63.6 & 36.4 & 100 \\
\hline & Married & $\mathbf{N}$ & 618 & 410 & 1028 \\
\hline & & $\%$ & 60.1 & 39.9 & 100 \\
\hline & $\begin{array}{l}\text { All other } \\
\text { categories }\end{array}$ & $\mathbf{N}$ & 20 & 8 & 28 \\
\hline & & $\%$ & 71.4 & 28.6 & 100 \\
\hline \multirow[t]{4}{*}{ No } & Single & $\mathbf{N}$ & 93 & 155 & 248 \\
\hline & & $\%$ & 37.5 & 62.5 & 100 \\
\hline & Married & $\mathbf{N}$ & 169 & 134 & 303 \\
\hline & & $\%$ & 55.8 & 44.2 & 100 \\
\hline
\end{tabular}




\begin{tabular}{lcccc}
\hline $\begin{array}{l}\text { All other } \\
\text { categories }\end{array}$ & $\mathbf{N}$ & 18 & 8 & 26 \\
& $\%$ & 48.5 & 51.5 & 100 \\
\hline
\end{tabular}

Type of first feed by marital status and private health insurance is a significant 3-way interaction ( $x 211.23, \mathrm{df}=2, \mathrm{P}=0.004)$. The odds ratio is 2.92 with a $95 \%$ confidence interval $(\mathrm{Cl})$ of 1.83-4.65 indicating that the odds of breastfeeding is significantly greater for single mothers with private health insurance compared with single mothers without private health insurance. This is not the case for married mothers, with an odds ratio of 1.20 (95\% Cl 0.92-1.54).

The odds ratio of breastfeeding due to insurance status, 2.92 for single mothers and 1.20 for married mothers, are significantly different, indicating that marital status affects the odds of whether a mother with private health insurance will breastfeed.

Table 4: Observed frequencies and percentages for type of first feed, how mother was fed and health insurance status

\begin{tabular}{llcccc}
\hline $\begin{array}{l}\text { Private } \\
\text { health } \\
\text { insurance }\end{array}$ & $\begin{array}{l}\text { How } \\
\text { mother was } \\
\text { fed }\end{array}$ & & $\begin{array}{l}\text { Initiated } \\
\text { Breastfeeding }\end{array}$ & $\begin{array}{l}\text { Initiated } \\
\text { formula } \\
\text { feeding }\end{array}$ & Total \\
\hline Yes & Breastfed & $\mathbf{N}$ & 193 & 55 & 248 \\
& Formula fed & $\mathbf{N}$ & 77.8 & 22.2 & \\
& & $\mathbf{\%}$ & 56.4 & 372 & 864 \\
& & & & 43.6 & \\
\hline
\end{tabular}

11 


\begin{tabular}{|c|c|c|c|c|c|}
\hline & Don't know & $\mathbf{N}$ & 23 & 21 & 44 \\
\hline & & $\%$ & 52.3 & 47.7 & \\
\hline \multirow[t]{6}{*}{ No } & Breastfed & $\mathbf{N}$ & 133 & 42 & 175 \\
\hline & & $\%$ & 76 & 24 & \\
\hline & Formula fed & $\mathbf{N}$ & 140 & 244 & 384 \\
\hline & & $\%$ & 36.5 & 63.5 & \\
\hline & Don't know & $\mathbf{N}$ & 9 & 17 & 26 \\
\hline & & $\%$ & 34.6 & 65.4 & \\
\hline
\end{tabular}

Multivariate analysis establishes that having private health insurance mediates the effect of other socio economic variables when determining breastfeeding initiation. Additionally, having been breastfed as an infant is a significant predictor of breastfeeding, and remains the case irrespective of health insurance status. Type of first feed by how the mother was fed as an infant and private health insurance is a significant 3-way interaction $\left(x^{2} 7.184, d f=2, \mathrm{P}=0.028\right)$.

However, the odds ratio for mothers who were formula fed as infants and breastfed their own infants at birth is $1.54(95 \% \mathrm{Cl} 1.34-1.79)$ and $0.76(95 \% \mathrm{Cl} 0.69-0.84)$ for those without health insurance, indicating that the odds of breastfeeding are significantly greater for mothers who were formula fed as infants who had health insurance than for those without insurance.

Mothers who indicated that they do not know how they were fed as infants and have private health insurance are also more likely to initiate breastfeeding (OR $1.51,95 \% \mathrm{Cl}$ 0.83-2.74) than their counterparts without health insurance (OR 0.76, 95\% $\mathrm{Cl} 0.48-1.10$ ). 


\section{Discussion}

The breastfeeding initiation rate in this study of $56 \%$ suggests that there would appear to be a marginal upward trend in the proportion of mothers breastfeeding in Ireland through the first decade of the twenty-first century, findings that have been corroborated by a recent cohort study [9]. However, this falls well below the $2 \%$ increase per year targeted in the national breastfeeding strategy [3].

This nationally representative study is the first to measure breastfeeding prospectively following discharge from hospital, since 1986 [10]. In the United Kingdom, national surveys have been undertaken every five years since 1975 and have enhanced the initiation of breastfeeding by allowing resources to be targeted more effectively at those mothers and communities requiring breastfeeding promotion [5]. The low rate of exclusive or even partial breastfeeding at six months indicates that very few women and infants in Ireland are receiving the benefits of breastfeeding for the duration recommended by the World Health Organisation [1]. Significantly, when findings for Irish women are viewed separately from those of other nationalities who responded to the survey, it is apparent that rates among Irish women remain consistently lower than those of their non-national counterparts. 
Our findings suggest, therefore, that any future recording system must take account of nationality when recording breastfeeding initiation and duration. In $2008,22.5 \%$ of all births in Ireland were to non-Irish-born women, which is an increase of 7\% from 2004 [4]. This information, combined with the knowledge from this and other studies $[10,11]$ that this group are more likely to breastfeed their infants, suggests that although NPRS figures indicate a marginal increase in the rate of breastfeeding initiation, this may not have occurred among Irish women and any increases that have occurred might result from the changing characteristics of mothers giving birth in Ireland, such as nationality [12]. This raises questions about the effectiveness of the national breastfeeding promotion strategy [13] in increasing breastfeeding rates among Irish women, as this policy initiative would appear to have had relatively little impact.

This study has also highlighted numerous pertinent and potentially modifiable factors associated with breastfeeding initiation in Ireland. Multivariate analysis demonstrates for the first time in Ireland that private health insurance mediates the effect of other pertinent socio-economic variables and should be considered when targeting interventions that aim to increase breastfeeding initiation. Data linking breastfeeding to socio-economic status has been well established in the literature [4,5]. Large increases in health insurance premiums of up to $45 \%$ since 2008 are likely to have reinforced the disparity between those who can and cannot afford health insurance, and consequently socio-economic status. While maternity care is provided free of charge for all women who are ordinarily resident in Ireland, under the Maternity and Infant Care Scheme, 
health-insurance status among pregnant women is a strong indicator of socio-economic status and, accordingly, of breastfeeding initiation. Interventions targeting particular socio-economic groups have been undertaken and show variable effectiveness with greater increases resulting from needs-based, informal repeat education ${ }^{13}$. This study demonstrated that such interventions should be considered and implemented, targeting Irish women from lower socio-economic groups, without health insurance, in an attempt to increase breastfeeding initiation in this context.

These data also highlight the need for a comprehensive, national system of monitoring breastfeeding rates at predetermined intervals, and any related or contributory factors, in order to assess the ongoing success of current, and any future, breastfeeding promotion strategies directed towards rates of initiation. The findings suggest the need to consider nationality when targeting future initiatives that support women to make informed decisions about infant feeding. Additionally, an urgent review of the national strategic action plan is required, alongside local and hospital initiatives that propose to promote and support breastfeeding in Ireland. These findings provide a basis for future interventions aimed at increasing breastfeeding rates in Ireland. These changes are essential in order to ensure optimal health outcomes for mothers and infants in Ireland.

Study limitations include the response of $33 \%$ of population, but congruence with findings of other research and with demographic data for Ireland provides re-assurance that the sample was representative of the overall population of women giving birth in 15 
Ireland. However, it is possible that over-sampling of women who were breastfeeding at birth may have occurred. Some midwives in distributing the questionnaire may have interpreted the focus of the survey as being to assess breastfeeding and, therefore, may have been more inclined to give the Phase 1 questionnaire to women who were breastfeeding rather than those who were formula feeding.

There was wide variation in response rates among the different sites. Thus, nonresponses may have introduced some bias into the findings. However, the large number of women who took part still provides extremely useful, unique data for understanding breastfeeding in Ireland at the end of the first decade of the twenty-first century. However, the low sample size achieved in some units, might limit the ability to make broader generalisations from the results to specific parts of Ireland.

\section{Acknowledgements}

The authors are extremely grateful to the study participants and to the Health Service Executive and Health Research Board who provided funding for this study.

\section{References:}

1. World Health Organization, Infant and young child nutrition: Global strategy on infant and young child feeding. World Health Organization, Geneva, 2003. 
2. Department of Health and Children, Breastfeeding in Ireland: A Five Year Strategic Action Plan. Department of Health and Children, The Stationery Office, Dublin, 2005.

3. European Commission, EU Project on Promotion of Breastfeeding in Europe, Protection, promotion and support for breastfeeding in Europe: a blueprint for action. European Commission, Luxembourg, 2002.

4. Economic and Social Research Institute and Department of Health and Children Perinatal Statistics Report 2006. HIPE \& NPRS Unit, Economic and Social Research Institute, Dublin, 2008.

5. Bolling K, Grant C, Hamlyn B, Thornton A. Infant Feeding Survey 2005. The Information Centre, Department of Health, Social Services and Public Safety U.K., London, 2007.

6. SPSS, Statistical Package for the Social Sciences. SPSS, Chicago, IL, 2008.

7. Cattaneo A, Davanzo R, Rofani L. Are data on the prevalence and duration of breastfeeding reliable? Acta Paediatrica 2000; 89(1): 88-93.

8. World Health Organization, Infant and young child nutrition: Global strategy on infant and young child feeding. World Health Organization, Geneva, 2003. 
9. Ladewig E.L., Hayes C., Browne J., Layte R., Reulbach U. The influence of ethnicity on breastfeeding rates in Ireland: a cross-sectional study. Journal of Epidemiology and Community Health 2013; 68(4): 356-362.

10. McSweeney M. National Survey of infant feeding practices. Health Education Bureau, Dublin, 1986.

11. Tarrant R. An investigation of the diets of infants born in Ireland during the first six months of life. School of Biological Sciences, Vol. Doctor of philosophy. Dublin Institute of Technology, Dublin, 2008.

12. Brick A, Nolan A. Explaining the increase in breastfeeding at hospital discharge in Ireland, 2004-2010. Irish Journal of Medical Science 2014; 183(3): 333-339.

13. Renfrew MJ, McCormick FM, Wade A, Quinn B, Dowswell T. Support for healthy breastfeeding mothers with healthy term babies. Cochrane Database of Systematic Reviews 2012; (5): CD001141. 